\title{
STRUCTURAL FIRE BEHAVIOUR OF Z PURLINS
}

\author{
Ivo Schwarz ${ }^{\mathrm{a}}$,Martin Slatinka ${ }^{\mathrm{a}}$, Michal Jandera ${ }^{\mathrm{a}}$ \\ ${ }^{\mathrm{a}}$ Czech technical University in Prague, Faculty of Steel and Timber Structures, Czech Republic
}

\begin{abstract}
Cold-formed sections are very common and efficient as secondary load-caring structural members. But the current European design standard EN 1993-1-2 sets the limiting temperature for the Class 4 sections to $350^{\circ} \mathrm{C}$ which is generallyvery conservative approach.This paper is focused on the thinwalled profilebehaviourin case offire. In particular, the paper describes transition from the beam to fibre behaviour of a $\mathrm{Z}$ purlin. A sophisticated shell element FE model is shown and compared to the test. Later, a more practical (Engineering) model neglecting the bending stiffness entirely is made and compared to the previous results. The conclusions show, that such simplified description of real behaviour is possible to be used after the bending capacity of the member is exceeded and predicts the forces to connection well.
\end{abstract}

Keywords:fire design, cold-formed section, thin-walled structure, Z purlin

\section{INTRODUCTION}

The typical uses of cold-formed sections are for single-storey buildings and other light weight constructions. Among the main benefits, the weight to resistance ratio and easy assembly plays important role.However, in the case of fire, the low weight and section slenderness may cause higher increase of temperature in the member and could be therefore seen as disadvantageous. Also, the design standard EN 1993-1-2, 2005sets the maximum temperature for the applicability of the standard to Class 4 sections to $350^{\circ} \mathrm{C}$ which is clearly very limiting and conservative as was shown byLu et al., 2010. In case of fire, the material characteristicsare reduced according to the EN 19931-2, where the French National Annex of the Eurocode gives also a separate values for cold-formed material. These were used in the presented study, where the purlin resistance is not limited by its bending capacity but catenary action is also allowed. This design method can save substantial costs of fire protection measures (e.g. spraying, coating, cladding, sufficiently massive cross-section...) in case when higher fire resistance is needed.The presented study shows a comparison of experimentally determined behaviour of $\mathrm{Z}$ purlins with simulations inAbaqus software as well as possible simplification of behaviour for an engineering design.

\section{DESIGN APPROACH}

Thedesign of steel structures under fire conditions is based on the calculation of bearing capacity of a structural element with reduced characteristics of material when using a design standard.In the design of beams with relatively small deflections, there is no influence of catenary action (catenary action in a member with horizontal support at its ends). Whereas for beams with large deflections (where the bending stiffness is very small) the opposite is true. This may be also partially affected by stiffness of the supports, but this was not considered in the current study.

This behaviour is explainedin Fig. 1 which indicates the catenary action for a continuous load. It is determined from the moment resistance of the horizontal forces on the member sag (vertical deflection), see $E q$. (1).The resistance of the member isthan not limited by the moment resistance but its tensile resistance.However, the connections or the supporting structure resistance may be limiting.

$$
F \cdot \delta \approx M
$$

where $F \quad$ is a horizontal force acting in the support, 
When considering the member behaviour described by the catenary action in a structural design it is necessary to take into account two factors: a possible limit of the vertical deflection and secondly the horizontal reactions in the supports, which must be transferred by the supporting structure.

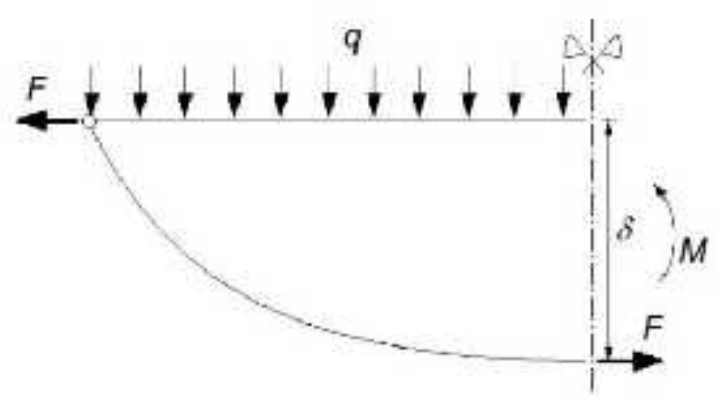

Fig. 1 Principle of catenary action on a beam

\section{FIRE TEST}

\subsection{Profiles}

A fire test was done for $\mathrm{Z}$ profiles of height $200 \mathrm{~mm}$ and thickness $1.5 \mathrm{~mm}$. These were spanned for $6 \mathrm{~m}$ (inside the furnace) with an overhanging part of $2.5 \mathrm{~m}$ on one side (outside the furnace). This overhanging part was aimed to simulate an internal support of a continuous beam. At this support, a sleeve system connection was used. This means that one member was used for the span, second for the cantilevered part and a thicker $(2.0 \mathrm{~mm})$ member interconnected both members at the hogging moment area (internal support region). The geometry and used profiles could be seen also in Fig. 2 . All profiles were made of steel S350 GD.

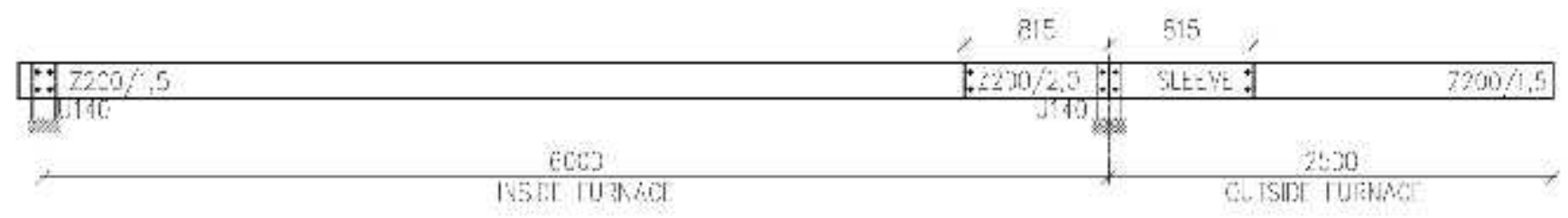

Fig. 2 Tested Z purlins

\subsection{Load}

The sections and load were chosen to represent a realistic example of a roof structural member (purlin). The load was based on combination for ultimate limit state for normal temperature. It considered a sandwich panel self-weight $0.15 \mathrm{kN} / \mathrm{m}^{2}\left(\gamma_{\mathrm{G}}\right.$ is 1.35$)$ and snow load $0.7 \mathrm{kN} / \mathrm{m}^{2}$ ( $\gamma_{\mathrm{Q}}$ is 1.5) and would represent more than $90 \%$ use of the member in normal conditions. For the combination in case of fire the partial safety factors $\left(\gamma_{\mathrm{G}}\right.$ and $\left.\gamma_{\mathrm{Q}}\right)$ are considered 1.0 and combination factor for the snow load $\psi_{1,1}=0.2$.

\subsection{Temperature}

The average temperature per each member at mid-span and at the support is shown in Fig. 3 . Despite the furnace showed relatively uniform temperature distribution, the increase of the temperature was lower for the sections next to the support. This results from the fact, that the profile was doubled in the hogging moment area by the sleeve profile. But it canbe said, the temperature may be simply considered as uniform, only the ends of the beam were slightly colder during the initial stage. The connections to the supports were thermally insulated by mineral wool. 


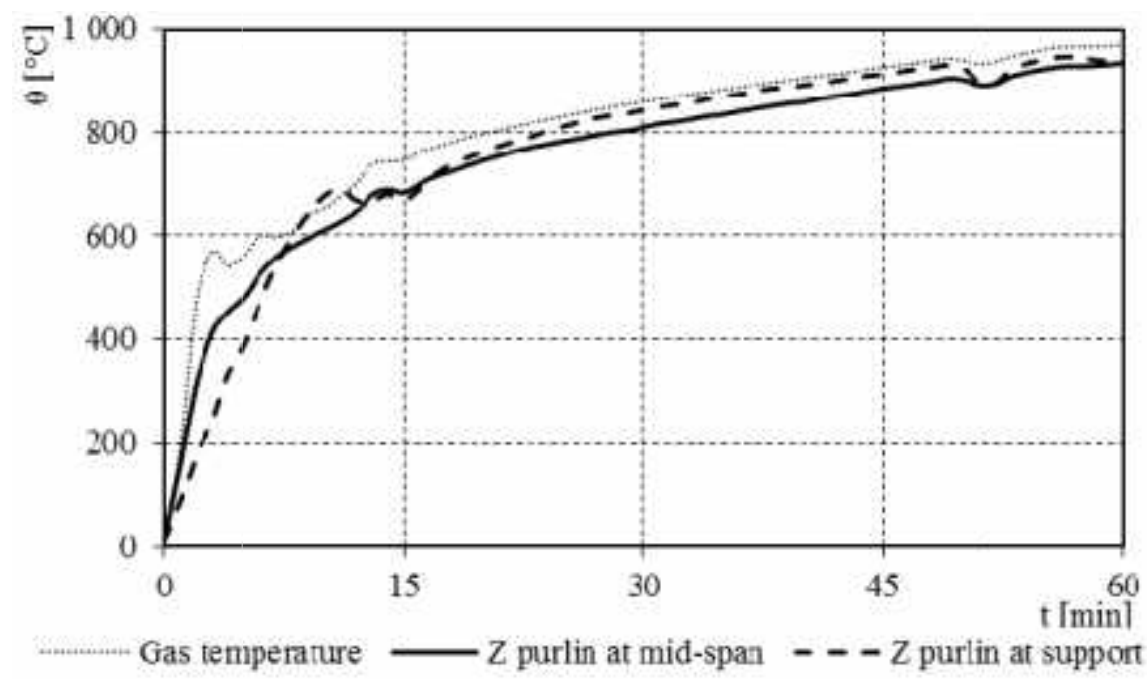

Fig. 3 Average temperature at mid-span and next to the support

\subsection{Deflection measurement}

The vertical deflection was measured per each member at the mid-span only. It is shown in the Fig. 4separately for the purlins with and without profiledsheeting at the top flange. Plus sign means the downward deflection.

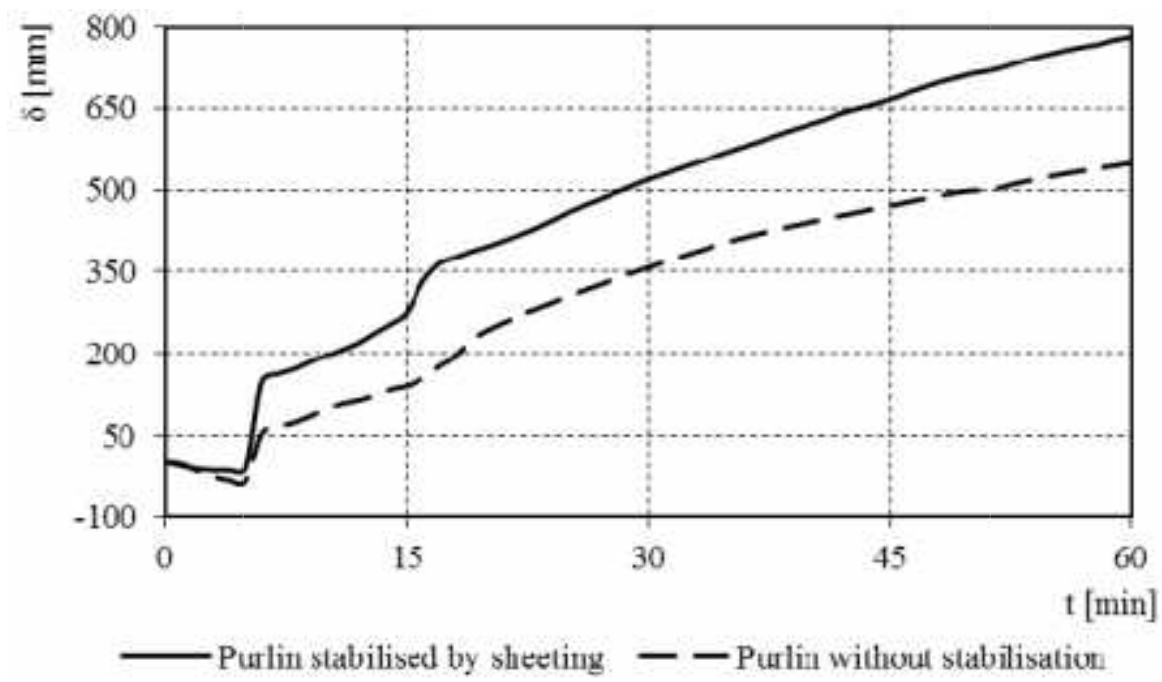

Fig. 4 Time-deflection diagram

\subsection{Conclusion of the experimental results}

During the test, the member buckled firstly with a significant contribution of an axial force induced by the thermal expansion. Later, when the axial force was relieved by deformations in the members, the deflection is controlled by thebending stiffness. After approx. 15 to 20 minutes of the test, the bending capacity is exceeded and thus a significant vertical deflection induced due to the catenary action.The detailed description of the fire tests was published previously by Schwarz and Jandera, 2014.

\section{FE MODEL}

\subsection{Shell element numerical model}

There were numerical models for the analysis made in the program Abaqus. The first numerical modelconsidered a 3D model of the purlin not restrained by the profiled sheeting. The shell element S4 was used and both local and global imperfections considered in the model. 
The model was rather simplified. The temperature was assumed as uniform over the whole member, no residual stresses were considered and corner strength enhancement was neglected. The overhanging part and the sleeve were found to have almost no influence on the behaviour and therefore were not modelled. The whole model including the supporting UPE profiles is shown in Fig. 5and also compared to the test after $60 \mathrm{~min}$.

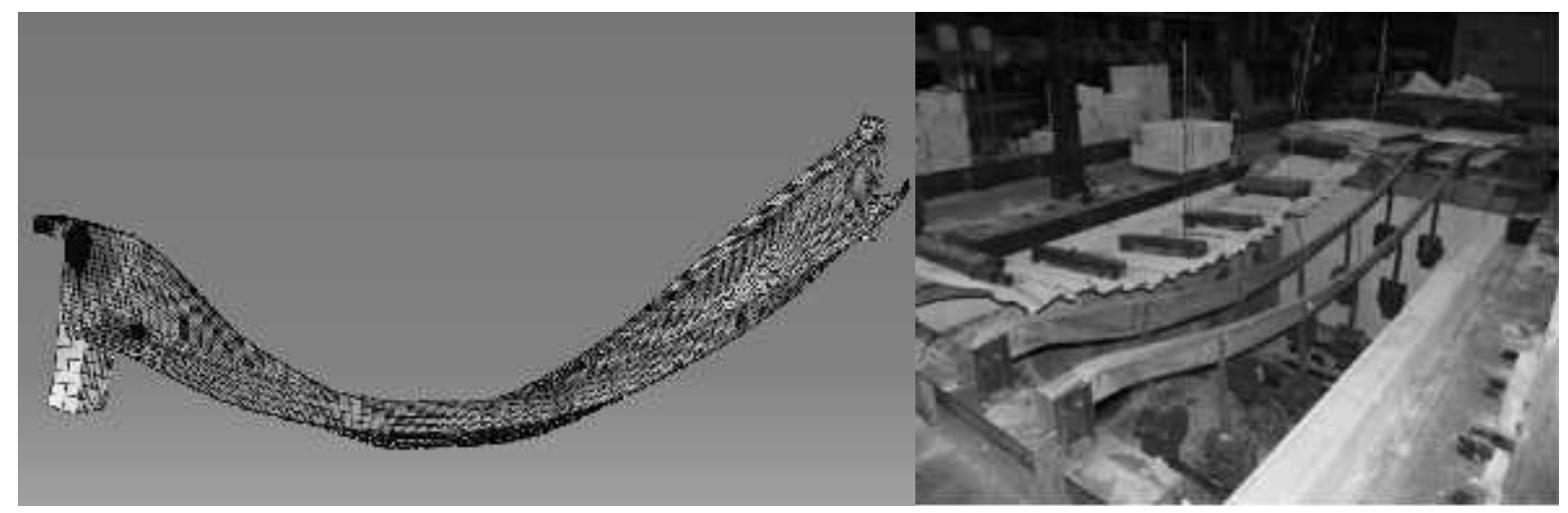

Fig. 5 Numerical model and test of a purlin (after $60 \mathrm{~min}$ of the fire test)

The material characteristics of the beam in the model were considered as nominal values of design standard EN 1993-1-3, 2006with reduction coefficients according to the French National Annex of EN 1993-1-2 for cold-formed steel.

The numerical analysis involving thermal expansion of the material describes only the initial stage of the test, until the buckling resistance of the element is reached.To model the whole fire test, the thermal expansion was neglected and the model therefore simplified for the initial stage of the test. The diagram onFig. 6comparestheanalysis with the test in terms of the vertical deflection at midspan. The numerical model gives a good prediction up to $20 \mathrm{~min}$ (around $800^{\circ} \mathrm{C}$ ) of the test. The prediction for higher temperatures is not so accurate, but the difference may be affected by the measurement itself. In the test measurement of vertical deflection, there is inherently included part of the horizontal deflection as well (due to the section rotation) whereas for the FE model not.

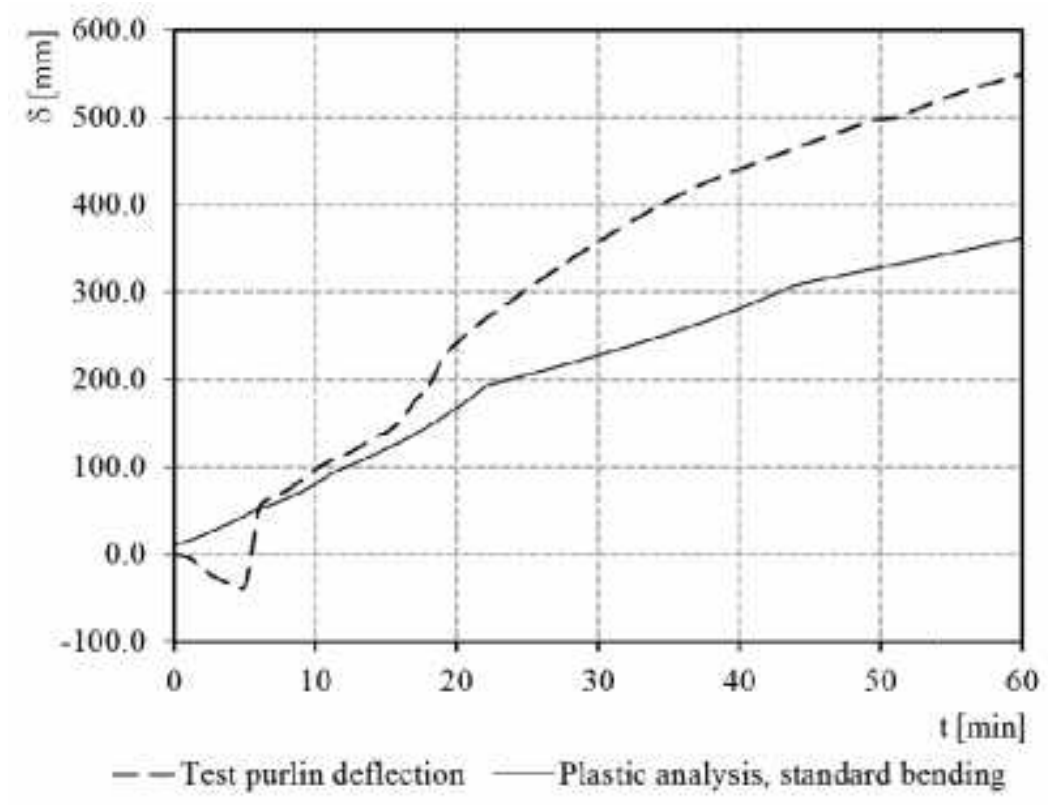

Fig. 6 Time-deflection diagram of the numerical model

\subsection{Fibre / beam element numerical model}

For comparison, the numerical model of fibre was created using a round bar section of the same section area as the investigated purlin. It is a beam element model pinned on both ends 
(supports).In the first phase,the simplificationleads toa significant increase of vertical deflection of the member with almost zero bending stiffnesswhich is exceeding the measured deflection evidently. For this stage, the model is in principle very inaccurate. On the other hand, this covers the temperatures which have smaller reduction of the material strength and where a standard bending verification is possible (and the bending resistance is satisfied). For the higher temperatures (above $700^{\circ} \mathrm{C}$ ), the predicted deflection is comparable with the more sophisticated shell model. In the chart onFig. 7, the time dependence of deformation for the fibre is given together with the experiment.

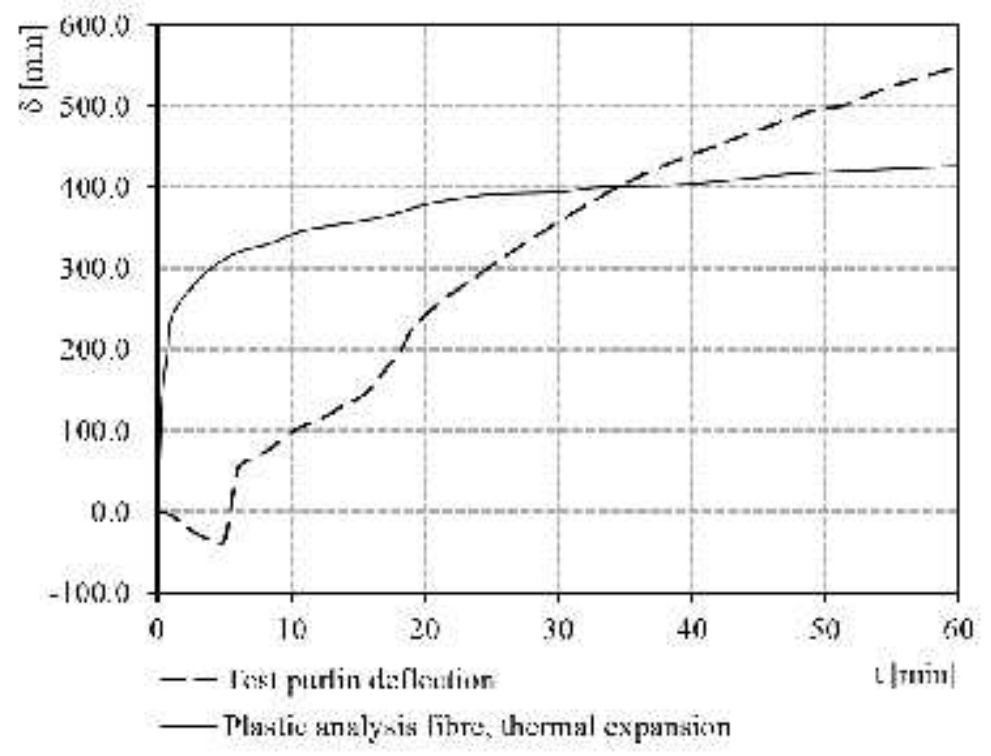

Fig. 7 Time-deflection diagram of the substitute numerical model

The main advantage of this simplification is the possibility to replace laborious, but geometrically accurate shell model when determining the internal forces in the connections. Of course a simple hand calculation would be also possible for a separate member and show identical result. However, in the real structure, the purlin is a part of a structural system and therefore affected by its stiffness. Therefore a simplified FE model is seen to be advantageous.

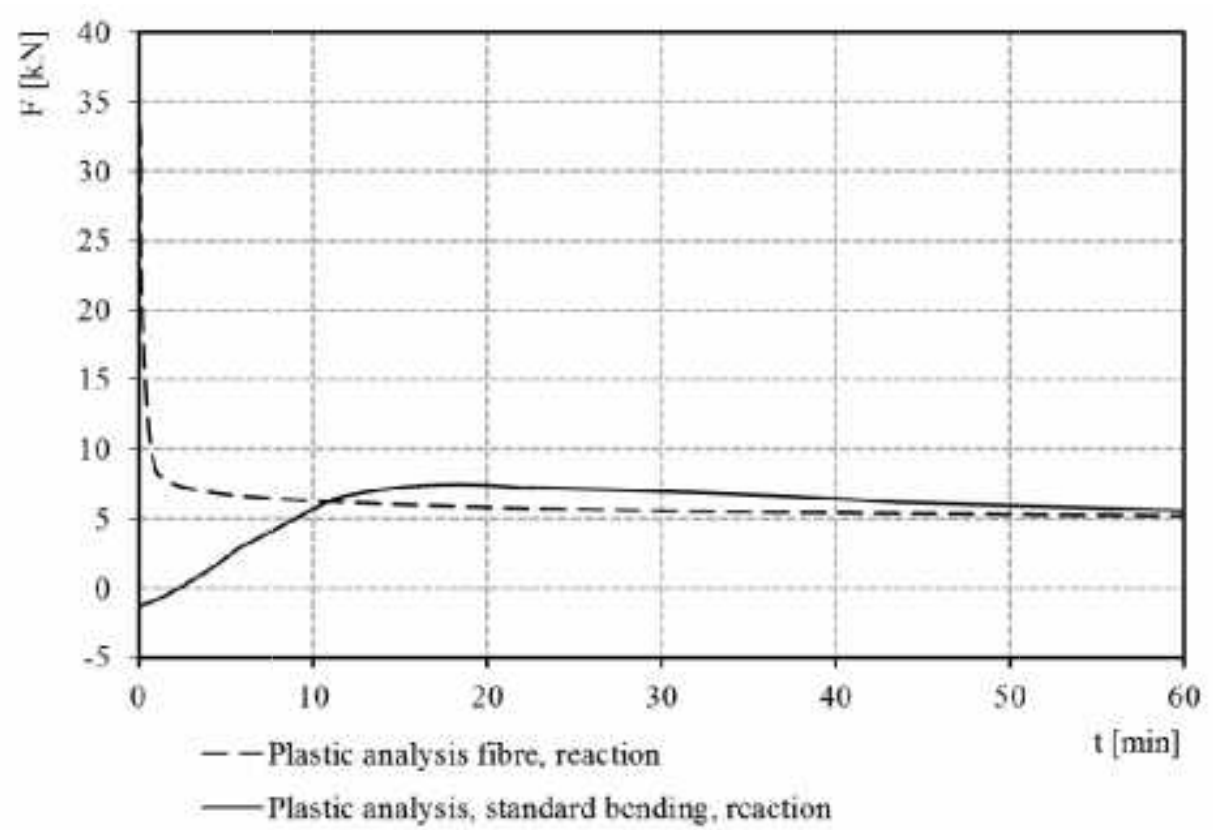

Fig. 8 Horizontal reaction in the purlin support 


\subsection{Comparison of the models in terms of the internal force prediction}

As was described already, the model of a purlin as a fibre is not describing the initial stage of the fire test suitably but on the other hand, is easy to use in the structural analysis. Fig. 8 shows the difference in the horizontal reactions calculated by the more sophisticated shell model and simple beam (fibre) model. It can be seen, that for the stage when the bending capacity of the purlin is exceeded, both models predict comparatively similar horizontal reactions which may be used for the connection verification (plus is for tension in the member). The simplification to the fibre behaviour is therefore possible.

\section{CONCLUSIONS}

The economical design of the horizontal bending steel components for fire is very difficult. The key factor is the determination of horizontal forces acting in supports. In the initial stage of a fire, the compressiveforce in member is induced by reactions due to thermal expansion of the material. However at the same time this force can't exceed the bearing capacity of the beam, as mentioned above. This horizontal force is relatively easy to determine and should be used as one of the design states for the purlin connection. It was also shown that after exceeding the bending capacity of the beam, the membercouldbe modelled in a simplified way as a drawn fibre (ignoringthe bending stiffness - catenary action) and on that basis the horizontal force in supports may be determined accurately enough. Even if the force is generally low, it may be critical considering thedecrease in the support resistance due to the elevatedtemperature.

\section{ACKNOWLEDGMENTS}

The article was supported by a research grant SGS 1611331A134.

\section{REFERENCES}

EN 1993-1-2, 2005. Eurocode 3: Design of steel structures - Part 1-2: General rules - Structural fire design, CEN, Belgium.

Lu W, Mäkeläinen P, Outinen J, 2010. Numerical simulation of cold-formed steel purlin behaviour in fire, Journal of Structural Mechanics, Vol. 43, No 1, p. 12-24.

Schwarz I., Jandera M., 2014. Structural fire behaviour of Z purlins, Eurosteel 2014 European Conference on Steel and Composite Structures, 10-12 September 2014, Naples, Italy, p. 402-408.

EN 1993-1-3, 2006. Eurocode 3: Design of steel structures - Part 1-3: General rules - Supplementary rules for cold-formed members and sheeting, CEN, Belgium. 